\title{
BMJ Open Depression, anxiety and stress during the COVID-19 pandemic: results from a New Zealand cohort study on mental well-being
}

\author{
Norina Gasteiger (D) , ${ }^{1}$ Kavita Vedhara (D) , ${ }^{2}$ Adam Massey, ${ }^{2} \mathrm{Ru} \mathrm{Jia},{ }^{2}$ Kieran Ayling, ${ }^{2}$ \\ Trudie Chalder, ${ }^{3}$ Carol Coupland, ${ }^{2}$ Elizabeth Broadbent (1) ${ }^{1}$
}

To cite: Gasteiger N, Vedhara K, Massey A, et al. Depression, anxiety and stress during the COVID-19 pandemic: results from a New Zealand cohort study on mental well-being. BMJ Open 2021;11:e045325. doi:10.1136/ bmjopen-2020-045325

- Prepublication history and additional supplemental material for this paper are available online. To view these files, please visit the journal online (http://dx.doi.org/10.1136/ bmjopen-2020-045325).

Received 29 September 2020 Revised 04 March 2021 Accepted 15 March 2021

\section{Check for updates}

C Author(s) (or their employer(s)) 2021. Re-use permitted under CC BY-NC. No commercial re-use. See rights and permissions. Published by BMJ.

${ }^{1}$ Psychological Medicine, The University of Auckland, Auckland, New Zealand

${ }^{2}$ Division of Primary Care, University of Nottingham, Nottingham, UK

${ }^{3}$ Psychological Medicine, Institute of Psychiatry,

Psychology \& Neuroscience, King's College London, London, UK

Correspondence to Dr Elizabeth Broadbent; e.broadbent@auckland.ac.nz

\section{ABSTRACT}

Objectives The COVID-19 pandemic has caused unprecedented disruption to daily life. This study investigated depression, anxiety and stress in New Zealand (NZ) during the first 10 weeks of the COVID-19 pandemic, and associated psychological and behavioural factors. It also compares the results with a similar cross-sectional study in the UK.

Design Cross-sectional study.

Setting NZ community cohort

Participants $\mathrm{N}=681$ adults ( $\geq 18$ years) in NZ. The cohort was predominantly female $(89 \%)$ with a mean age of 42 years (range 18-87). Most (74\%) identified as NZ European and almost half (46\%) were keyworkers. Most were non-smokers $(95 \%)$ and $20 \%$ identified themselves as having clinical risk factors which would put them at increased or greatest risk of COVID-19.

Main outcome measures Depression, anxiety, stress, positive mood and engagement in health behaviours (smoking, exercise, alcohol consumption).

Results Depression and anxiety significantly exceeded population norms $(p<0.0001)$. Being younger $(p<0.0001)$ and most at risk of COVID-19 $(p<0.05)$ were associated with greater depression, anxiety and stress. Greater positive mood, lower loneliness and greater exercise were protective factors for all outcomes $(p<0.0001)$. Smoking $(p=0.037)$ and alcohol consumption $(p<0.05)$ were associated with increased anxiety. Pet ownership was associated with lower depression $(\mathrm{p}=0.006)$ and anxiety $(p=0.008)$. When adjusting for age and gender differences, anxiety $(p=0.002)$ and stress $(p=0.007)$ were significantly lower in NZ than in the UK. The NZ sample reported lower perceived risk $(p<0.0001)$ and worry about COVID-19 $(p<0.0001)$ than the UK sample.

Conclusions The NZ population had higher depression and anxiety compared with population norms. Younger people and those most at risk of COVID-19 reported poorer mental health. Interventions should promote frequent exercise, and reduce loneliness and unhealthy behaviours.

\section{INTRODUCTION}

In 2020 the COVID-19 pandemic, caused by SARS-CoV-2, disrupted normal ways of living, globally. COVID-19 was first reported in December 2019 in Wuhan city, China. By late
Strengths and limitations of this study

- To our knowledge, this is the first study to explore mental well-being in a NZ population, during the COVID-19 pandemic.

- By using a similar design to a UK study, we can conclude that levels of anxiety, stress, perceived risk and worry about COVID-19 were significantly lower in the NZ sample.

- This study builds on previous work, by also exploring the impact of COVID-19 on health behaviours.

- Multiple modifiable and non-modifiable variables were explored, as well as their associations with validated measures for depression, anxiety, stress and positive mood.

- Due to the cross-sectional design, analysis of causal relationships and long-term impacts of the pandemic are not possible; and the self-selected sample may compromise generalisability.

January 2020, the $\mathrm{WHO}^{1}$ had acknowledged it as a public health emergency of international concern. Australia's Department of Health $^{2}$ confirmed their first COVID-19 case on 25 January and New Zealand's (NZ's) Ministry of Health ${ }^{3}$ on 28 February. By early July, COVID-19 had infected over 10 million people and caused more than 500000 mortalities worldwide. $^{4}$

Although a pandemic was declared, the extent and timeliness of public health and containment efforts differed across countries. Efforts included closing international borders, restricting domestic travel, introducing mandatory self-isolation for at-risk and symptomatic individuals, social distancing and wearing face masks in public areas. ${ }^{5} \mathrm{NZ}$ also introduced their now famous 'bubble' system, which restricted interaction to within households. Due to a fast response, NZ was able to control and contain the pandemic quickly, resulting in a total of 1528 cases and 22 deaths $(0.00045 \%$ of the population) by 
early July, ${ }^{3}$ compared with the UK's 311965 cases and 43575 deaths $(0.065 \%$ of the population) during the same period. ${ }^{6}$

A growing body of evidence documents clear clinical impacts of the COVID-19 pandemic. A systematic review of 19 studies conducted in Italy, Turkey, China, Spain, USA, Denmark, Nepal and Iran explored the impact of the pandemic on the mental health of the general public. ${ }^{7}$ This uncovered differing and often elevated rates of depression $(14.6 \%-48.3 \%)$, anxiety $(6.33 \%-50.9 \%)$ and stress $(8.1 \%-81.9 \%)$. Additionally, risk factors for psychological distress included being female, a student, unemployed, younger than 40 years or having a chronic illness. Evidence also shows disproportionate clinical impacts of the pandemic on other specific groups, such as older adults. ${ }^{8}$ Additionally, research in the USA and the UK also demonstrates that people from black, Asian and minority ethnic groups are more likely to be affected. ${ }^{9}$ According to data collected during the pandemic, key/ essential workers, especially health and care workers were not only more at risk of contracting the virus, but also of increased anxiety and depression. ${ }^{10}{ }^{11}$ A study by Liu et $a l^{10}$ in China reported the prevalence of depression and anxiety in medical staff to be over $50 \%$ and $40 \%$, respectively.

The pandemic and related containment efforts also introduced a multitude of additional stressors to populations, beyond bereavement and fear of infection. Changes such as wearing face masks, ${ }^{12}$ ceased interpersonal interaction through social distancing, loss of income ${ }^{13}$ and lockdowns have also been reported to impact mental health. Other possible stressors may include redundancies, border closures, changed events (eg, funerals and weddings) and significant changes in the working hours of the employed. In many countries like NZ and the UK, which enforced a lockdown, changes to daily living also included homeschooling and working remotely.

The effects of these stressors on the well-being of NZ and similar populations remains unknown, but are expected to pose a profound threat to psychological health. ${ }^{14}{ }^{15}$ Research on the general population in China during 'significant emergency' status of the pandemic indicated moderate or high psychological symptoms of phobic anxiety, obsessive compulsion, psychoticism and interpersonal sensitivity in more than $70 \%$ of participants. ${ }^{11}$ Another study with 1738 responses across 19 Chinese cities reported population mean scores indicating symptoms of post-traumatic stress disorder. ${ }^{16}$ Additionally, $28.8 \%$ of the sample met the threshold for moderate-to-severe anxiety. These scores persisted when measured fourweeks later. ${ }^{16}$ Research from the severe acute respiratory syndrome (SARS) and Middle East respiratory syndrome pandemics can also be drawn on to identify possible consequences. These show that isolation and quarantine may cause depression and anxiety, with symptoms such as anger presenting after only two weeks. ${ }^{17} 18$ It is important to explore whether these impacts are also replicated in other countries. ${ }^{19}$
The primary aim of the present study was to investigate levels of stress, anxiety and depression in NZ, and the psychological and behavioural factors associated with them. A secondary aim was to compare these results with the UK population. ${ }^{20}$ This was possible as the researchers from the UK and NZ study teams collaborated on the design of the research. We hypothesised that stress, depression and anxiety levels would be negatively affected during the first 10 weeks of social distancing, during the COVID-19 pandemic.

\section{METHODS}

\section{Study design and recruitment}

Recruitment began on 8 May 2020 and ended 30 days later, on 6 June. Participants were recruited via a mainstream and social media campaign that advertised a link to the study website. Advice was sought from Māori health advisors, and the study was advertised to as wide a network as possible to help reduce potential recruitment bias. Specifically, this included digital media, radio and social media (Facebook, Twitter and Instagram). Local district health boards, regional and city councils and various other organisations (universities, general practices and student and community groups representing older adults and ethnic minority groups) also shared the website with their networks. The website (www.covidstressstudy.com) contained the participant information sheet and the link to the online survey (content described under procedures and measures).

To be eligible to participate, individuals had to be over 18 years old, able to give informed consent, able to read English and reside in NZ. Participants gave their informed consent on the survey after reading an information sheet and consent form.

\section{Patient and public involvement}

This study used the same survey questions as the UK study by Jia $e t a t^{20}$ with the exception of additional questions on health behaviours. The design of the study, clarity of language in the participant information sheet and overall recruitment strategy were determined during a virtual patient and public involvement group on Microsoft Teams. ${ }^{20}$ The public were also involved in the recruitment strategy, by sharing the study with their networks and communities. Likewise, the NZ and UK research teams have been providing feedback to the public via the study website and the study social media pages (Twitter and Facebook).

\section{Sample size}

No upper limit was placed on the number of participants as the aim of the study was to explore the mental health status of the NZ population during the first 10 weeks of the pandemic with enough power to make comparisons between subgroups. A power calculation showed that 252 participants would be sufficient to detect an $\mathrm{R}^{2}$ value of 0.1 with $90 \%$ power and an $\alpha$ of 0.05 . 


\section{Procedures and measures}

Participants completed an online survey implemented through Qualtrics. This contained the consent form, questions on demographic information and validated measures capturing mental health outcomes. Anxiety was assessed using the Spitzer $e t a t^{21} 7$-item Generalized Anxiety Disorder (GAD-7) Scale. The 9-item Patient Health Questionnaire (PHQ-9) provided an index for depression and the 4-item Perceived Stress Scale (PSS-4) measured stress. ${ }^{22} 23$ These measures are widely used, validated and have good internal reliability: anxiety $(\alpha=0.88)$, depression $(\alpha=0.92)$ and stress $(\alpha=0.76) .^{21-23}$ Scale reliability in our sample was strong and consistent with that in literature: anxiety $(\alpha=0.92)$, depression $(\alpha=0.91)$ and stress $(\alpha=0.77)$.

Other modifiable and non-modifiable variables that could be directly related to these mental health outcomes or associated with increased risk of contracting COVID-19 were also measured. Non-modifiable variables included age, gender, ethnicity, keyworker status, living alone and risk of poor health consequences (ie, hospitalisation or mortality) due to COVID-19 (due to health issues). Modifiable factors included positive mood Scale of Positive and Negative Experience - Positive Feelings (SPANE-P) by Diener et $a l^{24}$ worry about contracting COVID-19, perceived loneliness, perceived risk of contracting COVID-19, owning a pet and health behaviours: smoking status and the frequency of exercise and alcohol consumption. More information about the measures is presented in online supplemental appendix 1. The same questions were used in the UK study for all variables except those pertaining to pet ownership and health behaviours.

\section{Statistical analysis}

Analyses were conducted in IBM SPSS V.26. Statistical significance was defined as $\mathrm{p}<0.05$.

Participant characteristics and outcome variables (depression, anxiety and stress scores) were first presented as descriptive statistics, using means and SD. Comparisons were made to established norms for the whole sample and subgroups based on age and gender using one-sample t-tests. Normality was assessed using histograms and scatterplots.

Univariable linear regressions were generated to explore the associations between the modifiable and non-modifiable variables and the outcomes. Multivariable linear regressions then explored the independent relationships of the non-modifiable variables on mental health outcomes. COVID-19 risk status (most at risk and at increased risk) was treated as a categorical variable in all models, with 'neither category' treated as the reference. Modifiable variables were then added in subsequent models, to explore the additional and independent contribution of these factors. Worry about COVID-19 was treated as a categorical variable in all models, with 'occasional worry' treated as the reference. Smoking status, gender and keyworker status were treated as binary variables in the regressions.
Assumptions of linear regression and the presence of outliers were assessed graphically and variance inflation factors provided no evidence of multicollinearity between variables. Square root transformations were applied to depression and anxiety scores, to satisfy assumptions of normality and homoscedasticity of residuals and linearity with continuous variables. Twenty-four participants were not represented in the final multivariable model for perceived risk of COVID-19, as this question was not asked to participants who thought they had COVID-19 or were tested for it.

Depression and anxiety scores were also categorised according to established cut-offs indicating severity of symptoms (scores of $>10$ indicate moderate or severe levels). One-sample t-tests were generated to compare mean levels of depression, anxiety, stress and perceived risk of COVID-19 in NZ and a UK sample recruited during the COVID-19 pandemic using the same measures, including age and gender subgroups. ${ }^{20}$ Age-adjusted and gender-adjusted linear regressions were performed for depression, anxiety and stress scores, to account for differences between the NZ and UK populations (online supplemental appendix 2) $\chi^{2}$ Tests were also generated to investigate differences in worry about COVID-19, between the two samples.

\section{RESULTS}

\section{Participant characteristics}

Fifty-nine per cent ( $\mathrm{n}=1846$ ) of visitors to the study website came through direct access, such as via the website URL or by clicking a URL linked in an email. A further 828 visits $(26 \%)$ came through Facebook, $124(4 \%)$ came from Instagram and $26(1 \%)$ came through Twitter. Ten per cent $(n=308)$ came from other websites, linked to the study web page.

A total of 789 individuals were recruited. The survey was completed in full by $86 \%$ of those who started it. This meant that there was missing data for 108 people. Consequently, these 108 were excluded from the analyses, leaving 681 study participants.

Table 1 summarises the main characteristics of the participants and reveals that our sample was predominantly female and aged between 18 years and 87 years, with a mean age of 42 years $(\mathrm{SD}=16)$. Participants resided across NZ and included representation from both the North and the South Islands. Most $(74 \%)$ identified as NZ European and 26.1\% came from ethnic minority groups or identified as 'other'. Almost half $(46 \%)$ were keyworkers. Most (85\%) lived with others and were nonsmokers $(95 \%)$. More than half $(57 \%)$ owned a pet, and $20 \%$ identified themselves as having clinical risk factors which would put them at increased or greatest risk of COVID-19.

The NZ sample were slightly older than the general $\mathrm{NZ}$ population. In the NZ sample, the median age of participants was 40 years, compared with 37.4 years of the general population (Statistics New Zealand, 2019). Men 
Table 1 Participant demographics $(n=681)$

\begin{tabular}{ll}
\hline & Participants \\
\hline Gender & n (\%) \\
Male & $68(10.0 \%)$ \\
Female & $608(89.3 \%)$ \\
Other & $4(0.6 \%)$ \\
Prefer not to say & $1(0.1 \%)$ \\
Age groups (years) & \\
\hline $18-24$ & $114(16.7 \%)$ \\
$25-34$ & $173(25.4 \%)$ \\
$35-44$ & $100(14.7 \%)$ \\
$45-54$ & $124(18.2 \%)$ \\
$55-64$ & $102(15.0 \%)$ \\
$65-74$ & $47(6.9 \%)$ \\
$\geq 75$ & $21(3.1 \%)$
\end{tabular}

Ethnicity

$\begin{array}{ll}\text { New Zealand/European } & 503(73.9 \%) \\ \text { Māori } & 14(2.1 \%) \\ \text { Samoan } & 5(0.7 \%) \\ \text { Cook Island Māori } & 1(0.1 \%) \\ \text { Chinese } & 19(2.8 \%) \\ \text { Indian } & 20(2.9 \%) \\ \text { Other } & 119(17.5 \%)\end{array}$

Relationship status

Single, never married

$155(22.8 \%)$

Single, divorced or widowed

$66(9.7 \%)$

In a relationship/married but living apart 47 (6.9\%)

In a relationship/married and cohabiting 408 (59.9\%)

Prefer not to say $5(0.7 \%)$

Education (highest level of attainment)

\begin{tabular}{ll} 
None & $6(0.9 \%)$ \\
Seventh grade or lower (primary school) & $4(0.6 \%)$ \\
Levels 5 and 6 diploma & $134(19.7 \%)$ \\
Bachelor's degree & $36(5.3 \%$ \\
Postgraduate & $161(23.6 \%)$ \\
Other (eg, Wānanga-Iwi) & $311(45.7 \%)$ \\
Place of residence & $29(4.3 \%)$ \\
Northland & \\
Auckland & $11(1.6 \%)$ \\
Waikato & $292(42.9 \%)$ \\
Bay of Plenty/Gisborne & $69(10.1 \%)$ \\
Hawkes Bay & $19(2.8 \%)$ \\
Taranaki & $22(3.2 \%)$ \\
Manawhatu-Whanganui & $22(3.2 \%)$ \\
Wellington & $18(2.6 \%)$ \\
\hline
\end{tabular}

Continued
Table 1 Continued

\begin{tabular}{ll} 
& Participants \\
\hline Nelson/Tasman/Marlborough & n (\%) \\
West Coast & $57(8.4 \%)$ \\
Canterbury & $20(2.9 \%)$ \\
Otago & $61(9.0 \%)$ \\
Southland & $12(1.8 \%)$ \\
\hline
\end{tabular}

Keyworker status

Health, social care or relevant related 224 (32.9\%) support worker

Teacher or childcare worker still travelling 14 (2.1\%) in to work

Transport worker still travelling in to work $1(0.1 \%)$

Food chain worker (eg, production, sale, 7 (1.0\%) delivery)

Key public services worker (eg, justice 7 (1.0\%) staff, public service journalist or mortuary worker)

Local or national government worker 16 (2.3\%) delivering essential public services

Utility worker (eg, energy, sewerage, $\quad 3(0.4 \%)$ postal service)

Public safety or national security worker $3(0.4 \%)$

Worker involved in medicines or protective $2(0.3 \%)$ equipment production or distribution

Other 'keyworker' role not listed 33 (4.8\%)

Not a keyworker $\quad 371$ (54.5\%)

Living alone (or with others)

Living alone $72(10.6 \%)$

Living with others 609 (84.9\%)

COVID-19 risk status

Most at risk (eg, suffering from advanced 48 (7.0\%) cancer, severe asthma/COPD, etc)

At increased risk (eg, being pregnant, 90 (13.2\%) aged over 70 years, etc)

Not at risk

$543(79.7 \%)$

Pet ownership

Yes

$389(57.1 \%)$

No

$292(42.9 \%$

Health behaviours

$\begin{array}{ll}\text { Smoker } & 36(5.3 \%) \\ \text { Non-smoker } & 645(94.7 \%) \\ \text { Exercise frequency } & \\ \text { Every day } & 295(43.3 \%) \\ 2-3 \text { times a week } & 212(31.1 \%) \\ \text { Once a week } & 71(10.4 \%) \\ \text { Less than once a week } & 68(10.0 \%) \\ \text { Never } & 35(5.1 \%)\end{array}$

Continued 


\section{Table 1 Continued}

\begin{tabular}{ll}
\hline & Participants \\
\hline Alcohol consumption & $\mathbf{n}(\%)$ \\
\hline Daily & $65(9.5 \%)$ \\
4-6 times a week & $90(13.2 \%)$ \\
1-3 times a week & $219(32.2 \%)$ \\
Less than once a week & $103(15.1 \%)$ \\
Never & $204(30.0 \%)$ \\
\hline
\end{tabular}

COPD, Chronic Obstructive Pulmonary Disease; NCEA, National Certificates of Educational Achievement.

were under-represented in the study (10\%), and make up $49 \%$ of the general population (Statistics New Zealand, 2019).

The NZ sample overall were younger $(\mathrm{M}=42$ years) than the UK sample ( $M=44$ years) (Jia et al, 2020). This was also reflected in $42 \%$ of the NZ sample being younger than 34 years, compared with $29 \%$ of the UK sample. More women $(89 \%)$ and less men (10\%) participated in the NZ study compared with the UK sample $(85 \%$ and $15 \%$, respectively).

\section{Mental health status in NZ, compared with population norms and a UK cohort}

Depression and anxiety in the NZ sample were examined using the categories of the established cut-offs for depression and anxiety in the PHQ-9 and GAD-7 scales (see online supplemental appendix 1). Accordingly, $64 \%$ of participants reported symptoms of depression and 53\% reported symptoms of anxiety. Thirty-one per cent reported moderate-to-severe symptoms of depression, and $24 \%$ reported moderate-to-severe symptoms of anxiety.

Depression, anxiety and stress in the NZ cohort were compared with population norms (see table 2). The overall mean values for the depression and anxiety measures were significantly higher than previously reported population norms. ${ }^{25} 26$ Compared with the population norms, the means for both depression and anxiety were higher for both genders. The average scores for depression in the NZ sample were also significantly higher than the population norms for all age groups ranging from 25 years to 74 years. For anxiety, the means for those aged 25-64years were significantly higher than the established population norms. The data suggested no significant differences in stress scores by the NZ cohort when compared with the population norms. ${ }^{27}$

Table 3 presents mean depression, anxiety, stress and worry about COVID-19 scores in the NZ cohort, compared with a UK cohort recruited during the COVID-19 pandemic. ${ }^{20}$ In both the UK and NZ samples, all mean values for depression, anxiety and stress were higher in women than men and higher in younger age groups. The overall mean values in NZ were not significantly different to the UK sample. However, anxiety in women and participants aged $25-34$ years and $45-54$ years was significantly lower in the NZ sample.

When adjusting for age and gender differences between the UK and NZ samples, there was no significant difference in depression $(p=0.138)$. However, there was a significant difference between scores for anxiety $(\mathrm{p}=0.002)$. Anxiety scores were on average 0.15 lower $(95 \%$ CI -0.25 to -0.05$)$ in NZ than UK. There was also a significant difference between stress scores $(p=0.007)$. Stress scores were on average 0.36 lower $(95 \%$ CI -0.63 to -0.10 ) in NZ than UK.

A $\chi^{2}$ test was performed to examine the differences in worry about COVID-19 between NZ and the UK (table 3). A greater proportion of people in the UK sample reported worrying about COVID-19 most of the time, much of the time, and occasionally, and a smaller proportion reported never worrying about it compared with the NZ sample, $\chi^{2}(3, \mathrm{n}=3777)=163.27, \mathrm{p}=<0.001$. The NZ sample also reported lower levels of perceived risk of COVID-19 $(M=2.29, S D=1.65)$ than the UK sample $(M=4.75, S D=2.2), t(656)=-38.10, \mathrm{p}=<0.0001$.

\section{Individuals most at risk of depression, anxiety and stress}

Multivariable models explored the associations between non-modifiable explanatory variables and depression, anxiety and stress (table 4 ). The outcome variables by gender and age groups are also presented in online supplemental appendix 4 . Being younger and being most at risk for COVID-19 were independently significantly associated with greater levels of depression. This model accounted for $10 \%$ of the variance in depression scores. Being younger and being most at risk for COVID-19 were also independently significantly associated with greater levels of anxiety. This model accounted for $8 \%$ of the variance in anxiety scores. For stress, being younger and being most and at increased risk for COVID-19 were independently significantly associated with greater stress. This model accounted for $9 \%$ of the variance in stress scores.

\section{Mental health status and modifiable variables}

Modifiable explanatory variables included loneliness, positive mood, perceived risk of COVID-19 and worry about COVID-19. The cohort's mean score of loneliness was $3.91(\mathrm{SD}=2.8)$. The age group 18-24 years reported the highest level of loneliness $(M=5.21, S D=2.8)$, compared with the oldest age group who reported the lowest level $(M=1.95, S D=1.4)$. The mean score of positive mood was $19.97(S D=5.0)$. Again, the youngest age group presented the lowest mean score $(M=18.48, S D=4.7)$ and the oldest age group the highest $(M=23.9, S D=4.5)$. The mean score for perceived risk of COVID-19 was $2.29(S D=1.7)$. Of the whole cohort, $54 \%$ worried about COVID-19 occasionally, $37 \%$ never, $7 \%$ much of the time and $2 \%$ most of the time.

Other modifiable variables included health behaviours (smoking, exercise and alcohol consumption frequency) and pet ownership. A $\chi^{2}$ test of independence was performed to examine the relation between pet 


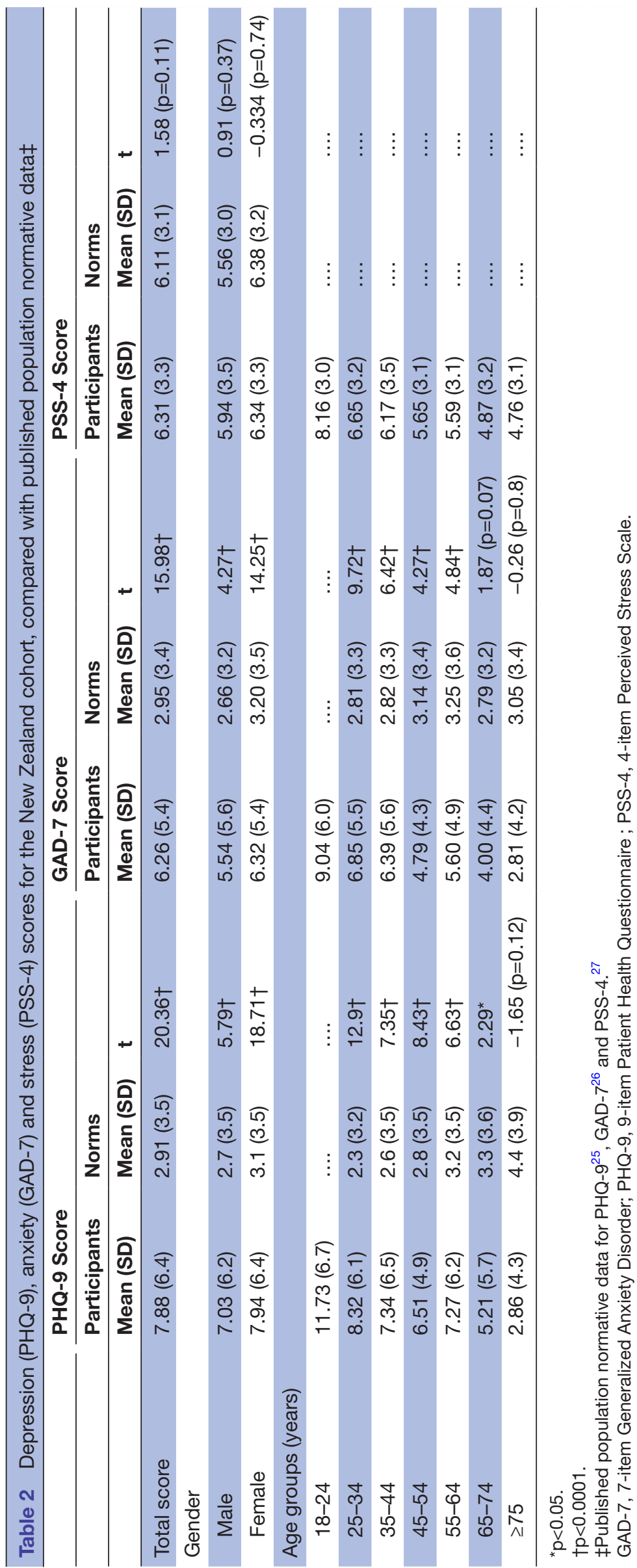




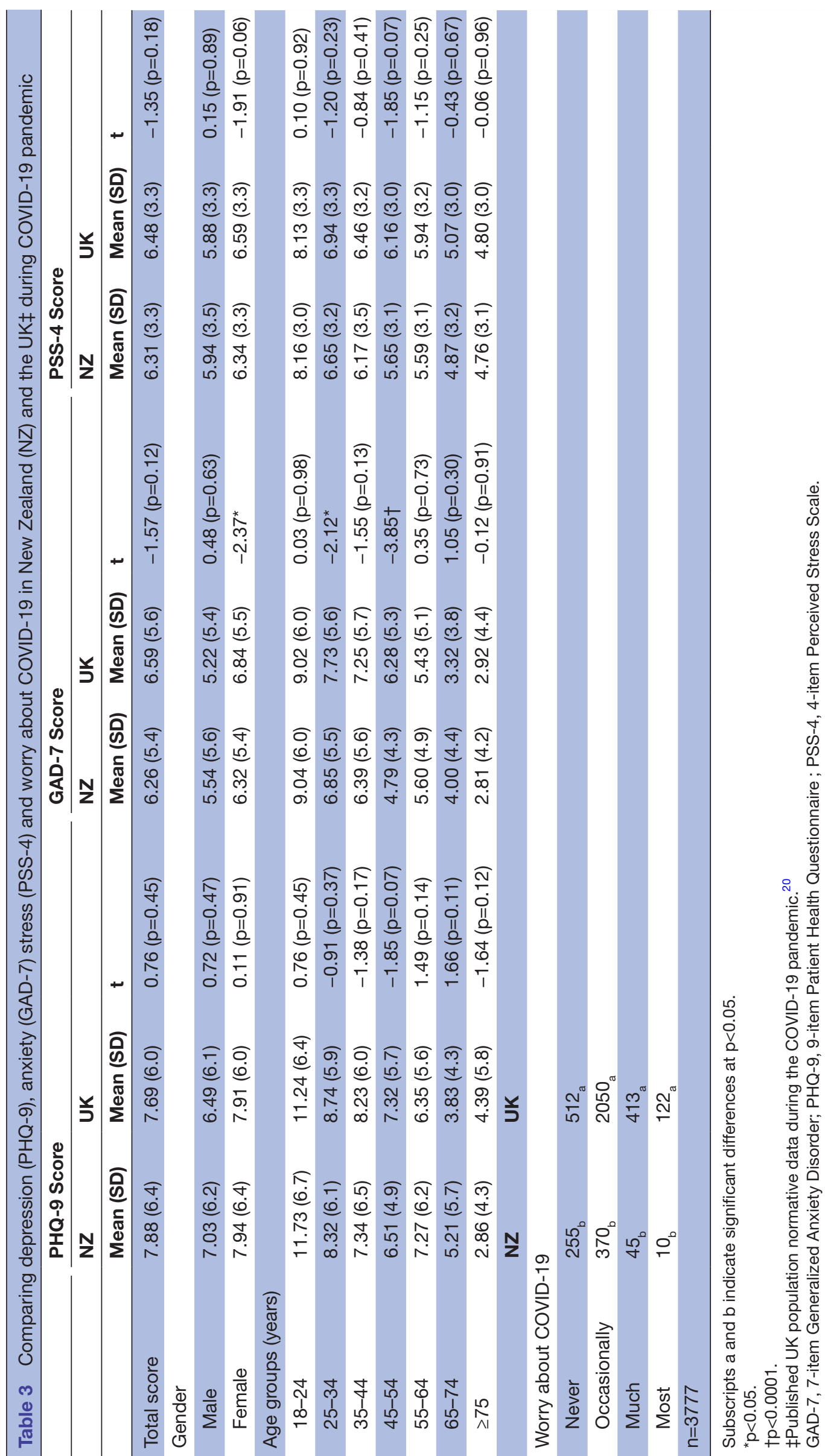


Table 4 Regression models showing associations between non-modifiable explanatory variables and depression, anxiety and stress scores

\begin{tabular}{|c|c|c|c|c|c|}
\hline $\mathrm{n}=681$ & B & $95 \% \mathrm{Cl}$ lower & $95 \% \mathrm{Cl}$ upper & $\beta$ & $P$ value \\
\hline \multicolumn{6}{|l|}{ PHQ-9 total score§ } \\
\hline Age (per decade) & -0.25 & -0.31 & -0.19 & -0.33 & $p<0.0001 \neq$ \\
\hline Female & 0.18 & -0.10 & 0.46 & 0.05 & 0.20 \\
\hline Live alone & 0.16 & -0.13 & 0.46 & 0.04 & 0.28 \\
\hline BAME background & -0.17 & -0.43 & 0.09 & -0.05 & 0.19 \\
\hline Keyworker & 0.06 & -0.13 & 0.24 & 0.02 & 0.54 \\
\hline \multicolumn{6}{|l|}{ COVID-19 risk status } \\
\hline Most at risk & 0.47 & 0.11 & 0.82 & 0.10 & $\mathrm{p}<0.05^{\star}$ \\
\hline Increased risk & 0.07 & -0.21 & 0.34 & 0.02 & 0.62 \\
\hline
\end{tabular}

Adjusted $\mathrm{R}^{2}=0.10$

GAD-7 total score§

\begin{tabular}{|c|c|c|c|c|c|}
\hline Age (per decade) & -0.22 & -0.28 & -0.17 & -0.30 & $\mathrm{p}<0.0001 \ddagger$ \\
\hline Female & 0.21 & -0.07 & 0.48 & 0.06 & 0.14 \\
\hline Live alone & 0.13 & -0.16 & 0.42 & 0.03 & 0.39 \\
\hline BAME background & -0.10 & -0.35 & 0.15 & -0.03 & 0.45 \\
\hline Keyworker & 0.01 & -0.17 & 0.18 & 0.00 & 0.96 \\
\hline \multicolumn{6}{|l|}{ COVID-19 risk status } \\
\hline Most at risk & 0.47 & 0.12 & 0.81 & 0.10 & $p<0.01 \dagger$ \\
\hline Increased risk & 0.19 & -0.08 & 0.46 & 0.05 & 0.17 \\
\hline \multicolumn{6}{|l|}{ Adjusted $R^{2}=0.080$} \\
\hline \multicolumn{6}{|l|}{ PSS-4 total score } \\
\hline Age (per decade) & -0.63 & -0.78 & -0.47 & -0.31 & $p<0.0001 \ddagger$ \\
\hline Female & 0.43 & -0.31 & 1.17 & 0.04 & 0.25 \\
\hline Live alone & 0.73 & -0.06 & 1.51 & 0.07 & 0.07 \\
\hline BAME background & 0.06 & -0.62 & 0.74 & 0.01 & 0.86 \\
\hline Keyworker & 0.40 & -0.08 & 0.88 & 0.06 & 0.10 \\
\hline \multicolumn{6}{|l|}{ COVID-19 risk status } \\
\hline Most at risk & 1.25 & 0.32 & 2.19 & 0.10 & $p<0.01 \dagger$ \\
\hline Increased risk & 0.74 & 0.01 & 1.47 & 0.08 & $p<0.05^{\star}$ \\
\hline
\end{tabular}

Adjusted $\mathrm{R}^{2}=0.09$

${ }^{*} \mathrm{p}<0.05$.

$\dagger \mathrm{p}<0.01$

$\neq \mathrm{p}<0.0001$.

§Square root transformation.

ПComparison reference group: neither category.

BAME, black, Asian and minority ethnic; GAD-7, 7-item Generalized Anxiety Disorder; PHQ-9, 9-item Patient Health Questionnaire ; PSS-4,

4-item Perceived Stress Scale.

ownership and exercise, and pet ownership and loneliness. The relation between pet ownership and exercise was not significant, $\chi^{2}(4, \mathrm{n}=681)=1.35, \mathrm{p}=0.854$. There was also not a significant difference in the loneliness scores for pet ownership; $\mathrm{t}(679)=0.57, \mathrm{p}=0.570$.

Modifiable explanatory variables were added into two multivariable models for depression (table 5). We observed that greater perceived loneliness and lower positive mood were independently and significantly associated with greater levels of depression, in addition to age, gender and being most at risk of contracting COVID-19. The model accounted for $56 \%$ of the variance in depression scores.

For modifiable health behaviours, those who owned a pet, or who exercised every day or exercised two to three times a week (compared with never) had significantly lower depression scores. The model accounted for $15 \%$ of the variance in depression scores.

Higher levels of perceived loneliness, lower positive mood and worrying about COVID-19 much of the time 


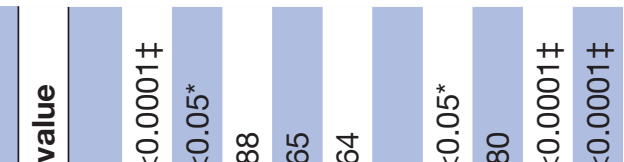

梈

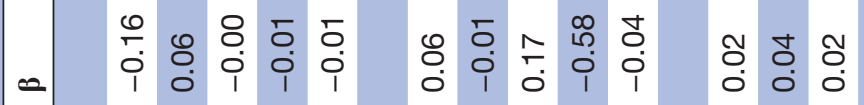

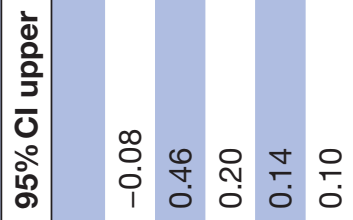

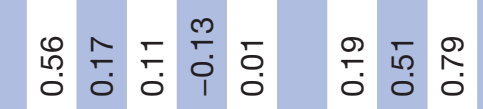

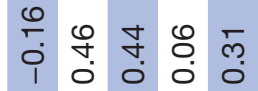

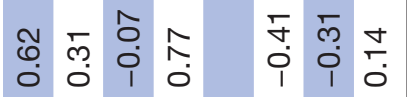

\section{离}

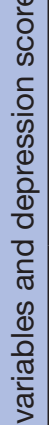

2
0
0
0
0

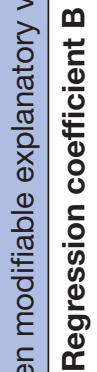

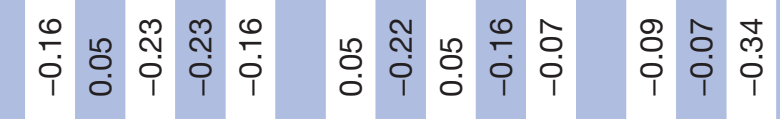

$\begin{array}{lllll}\infty & 8 & 10 & 0 & 0 \\ & 0 & 0 & 0 \\ 0 & 0 & 0 & 0 & 0 \\ 1 & 1 & 1 & 1 & 0 \\ 0 & 1\end{array}$

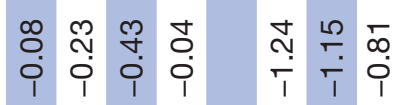

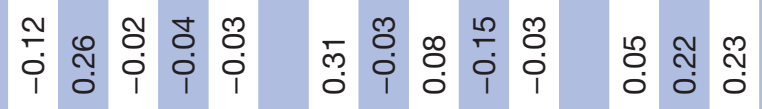

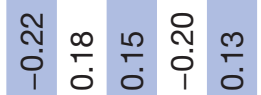

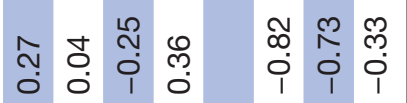

胥

:

๕

व क्ष

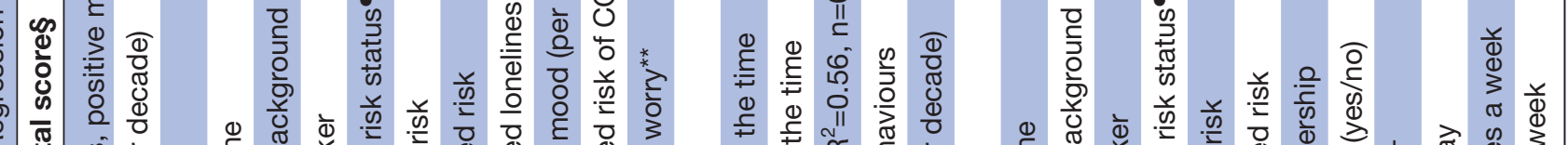

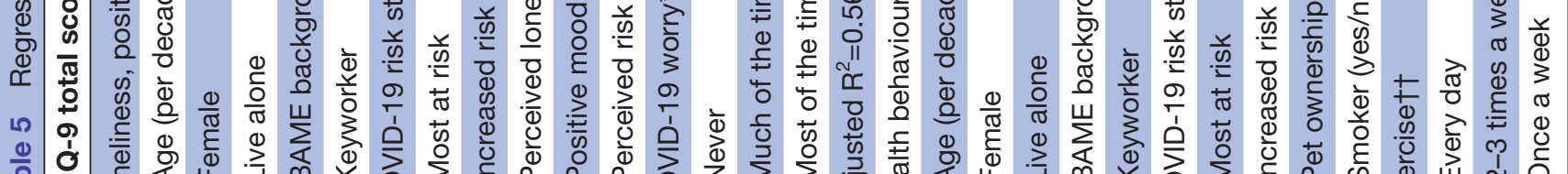

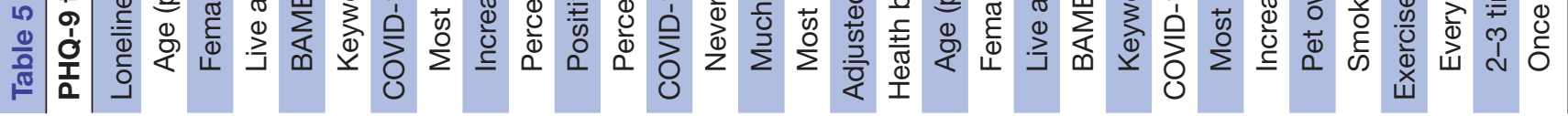

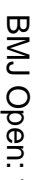

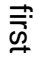

$\frac{\overline{0}}{\overline{\frac{0}{0}}}$

क

$\overrightarrow{\vec{\omega}}$

$\frac{0}{3}$

N

离

웅

离

ก

일

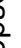

ㄱ. 


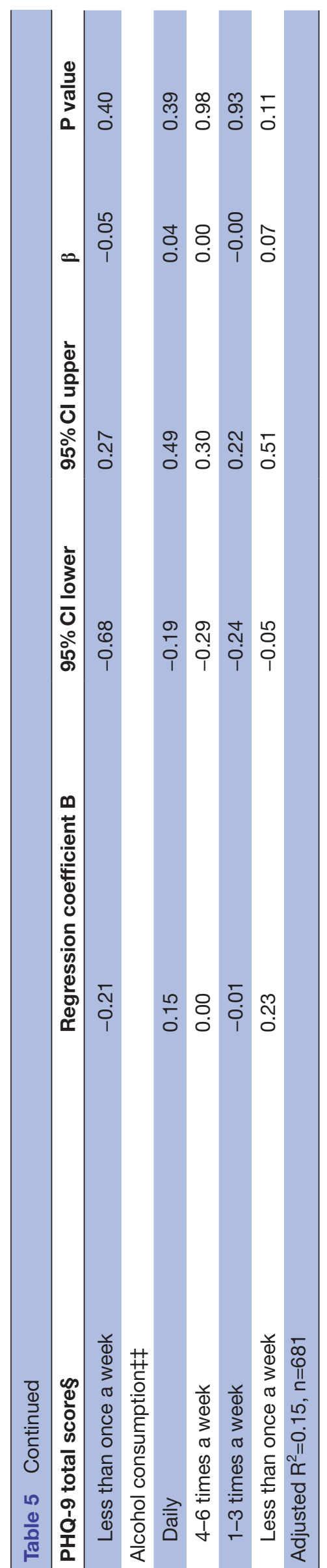

were independently and significantly associated with greater levels of anxiety, in addition to age and gender (table 6). Never worrying about COVID-19 was associated with lower levels of anxiety. The model accounted for approximately $54 \%$ of the variance in anxiety scores.

For modifiable health behaviours, smoking, consuming alcohol less than once a week, and consuming alcohol four to six times a week (compared with never) were independently and significantly associated with greater levels of anxiety, in addition to age. Those who owned a pet, and those who exercised every day, two to three times a week or once a week, compared with those who never exercised had significantly lower levels of anxiety. The model accounted for $13 \%$ of the variance in anxiety scores.

Higher levels of perceived loneliness, lower positive mood and greater perceived risk of COVID-19 were independently and significantly associated with higher levels of stress, in addition to age, gender and being most or at increased risk of contracting COVID-19 (table 7). The model accounted for $58 \%$ of the variance in stress scores.

For health behaviours, exercising every day, two to three times a week, once a week and less than once a week compared with no exercise were independently and significantly associated with lower levels of stress, in addition to age and being a keyworker. The model accounted for $13 \%$ of the variance in stress scores.

Table 1 in online supplemental appendix 5 presents the same regression models with the psychological predictors, but excluding perceived risk of COVID-19. This found similar results.

\section{DISCUSSION}

The effects of the COVID-19 pandemic and social distancing on the general population are expected to pose a profound threat to psychological health. ${ }^{1415}$ The findings of the present study build on existing literature exploring the impacts of the pandemic on mental health status, especially depression, anxiety and stress. To our knowledge, this is the first study that explores the mental well-being of the NZ population, during the COVID-19 pandemic. It uses a similar design to the research recently published by Jia $e t a l^{20}$ from the UK to enable for comparisons to be made, but builds on this, by also considering the associations of behaviours (smoking, exercise and alcohol consumption) and pet ownership on mental health during the pandemic.

As hypothesised, depression and anxiety were negatively affected during the first 10 weeks of social distancing, during the COVID-19 pandemic. This was evident in the NZ mean scores for depression and anxiety during the COVID-19 pandemic significantly exceeding population norms. This finding is consistent with other research conducted overseas during the pandemic. ${ }^{10} 1120$ Unsurprisingly, those at higher risk for COVID-19 were more likely to experience poorer mental health status. However, younger people aged 18-24 years were also 


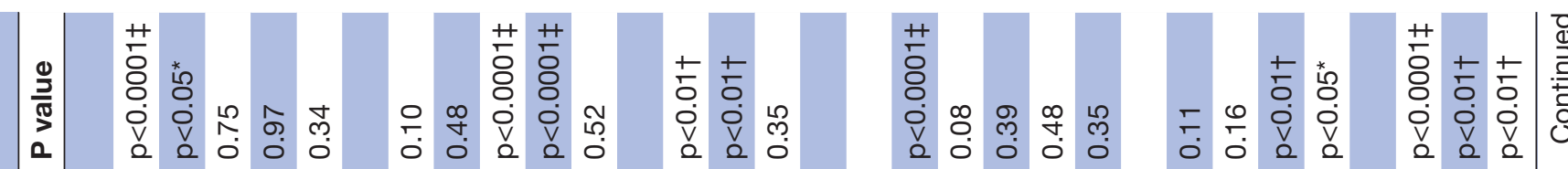

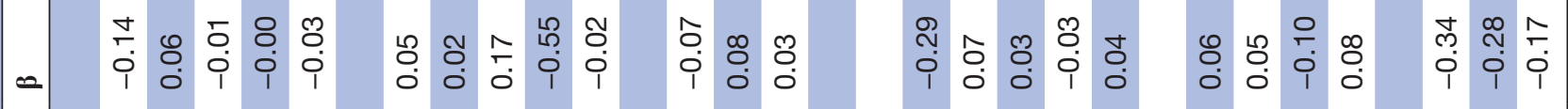

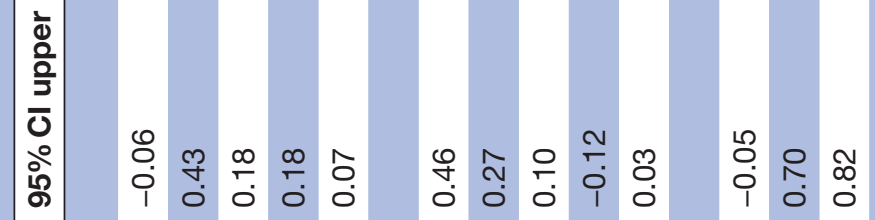

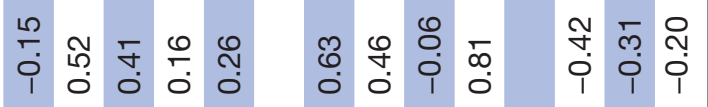

\section{音 \\  \\ 든}

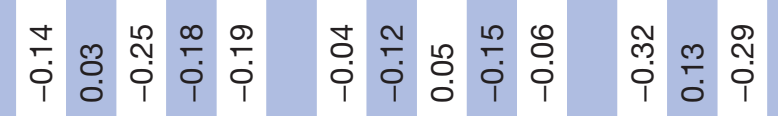

ヘ̦

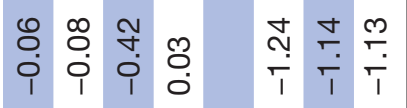

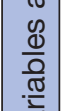

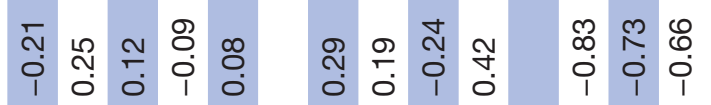

\section{离}

$\sum_{\substack{ \pm \\ \hline}}^{\infty}$

0
$\frac{0}{0}$
$\frac{0}{0}$
0

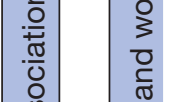

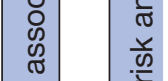

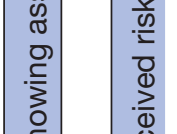

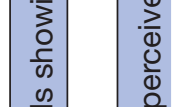

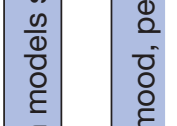

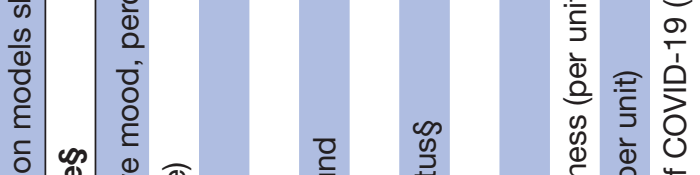

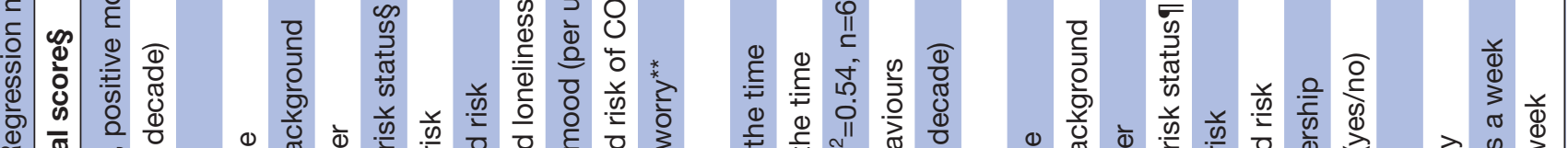

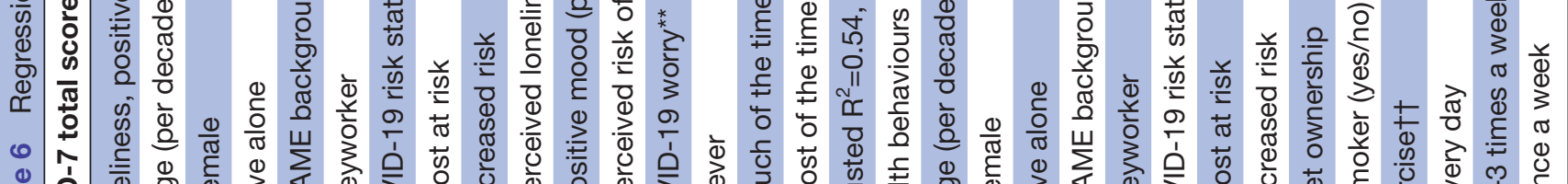

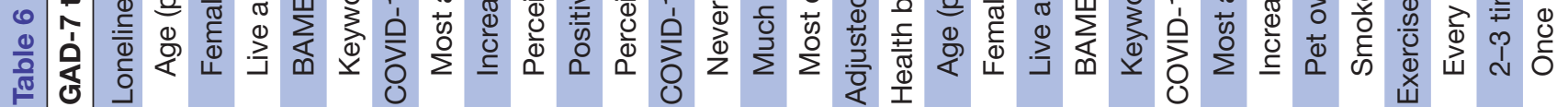




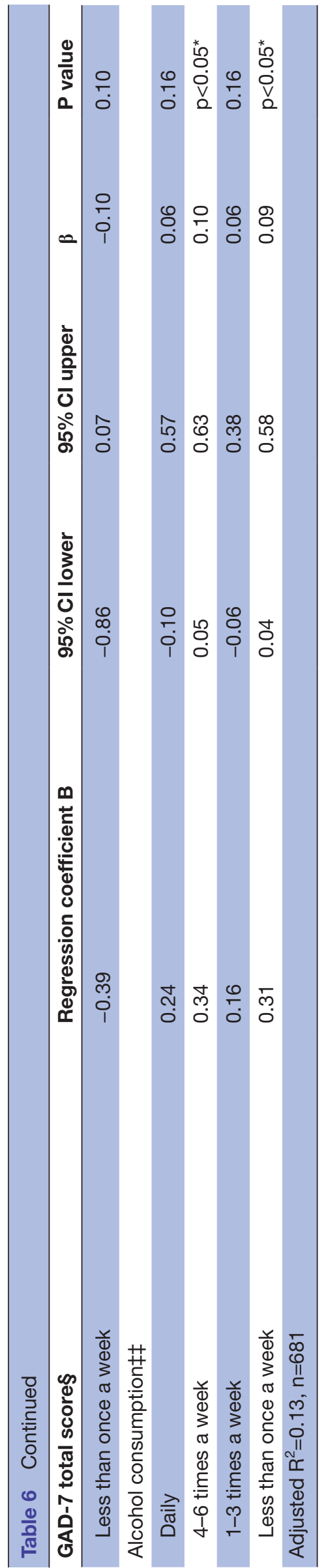

disproportionally affected and more likely to report greater levels of anxiety, stress and depression.

Some research from China and the Philippines explains why younger people may have been more impacted during the COVID-19 pandemic, highlighting that they were more likely to be students and that student status was a risk factor for anxiety, depression and stress. ${ }^{28} 29$ Many students experienced academic delays and significant changes to daily routine during the pandemic. ${ }^{30}$ Other research highlights that younger populations tend to generally have worse mental health outcomes. ${ }^{31-33}$ Common stressors that cause poor mental health in young adults include exams and study, paying rent, affording a house, pressure to succeed, career prospects, job instability, appearance and lower finances and living security. ${ }^{34}$ Older adults may have more experience with these stressors, so may be more resilient to them. The pandemic and social distancing regulations may have further exacerbated stress in younger populations, by causing unemployment and financial problems, limiting social interaction and support, and requiring students to study remotely while experiencing academic uncertainty. Ultimately, more psychological support is required for the NZ population during events such as pandemics, especially for younger people.

Poor mental health status was also associated with worry and heightened perceptions of risk of COVID-19. In the NZ cohort, worry about COVID-19 was associated with anxiety, and perceived risk of COVID-19 was associated with stress. Greater positive mood and lower perceived loneliness were protective factors for all outcomes. Previous literature has reinforced that the effects of positive mood are independent of negative mood. ${ }^{36} 37$ This means that individuals can be depressed or worried, but still report positive mood. However, the NZ sample demonstrated that positive mood protected against poorer mental well-being. It was unsurprising that lower perceived loneliness was a protective factor, as social capital significantly impacts well-being, stress, depression, quality of life, coping and health-promoting behaviours and adjustment. ${ }^{38} 39$ Similarly, a literature review by Leigh-Hunt $e t a t^{40}$ found that social isolation and loneliness are associated with worse health outcomes, as well as worse cardiovascular outcomes. Research from the SARS and Middle East respiratory syndrome pandemics have found similar results, whereby isolation and quarantine were postulated to cause depression and anxiety. ${ }^{17}{ }^{18} \mathrm{It}$ is possible that social isolation due to social distancing regulations during the COVID-19 pandemic may have amplified feelings of loneliness.

The present study builds on that by Jia $e t a l^{20}$ by highlighting that smoking and alcohol consumption were also associated with greater anxiety during the COVID-19 pandemic. It has been widely documented that people with poor mental health are more likely to engage in unhealthy behaviours such as smoking and frequent alcohol consumption. ${ }^{35} 41$ Unhealthy behaviours may be used as a coping mechanism to temporarily alleviate 


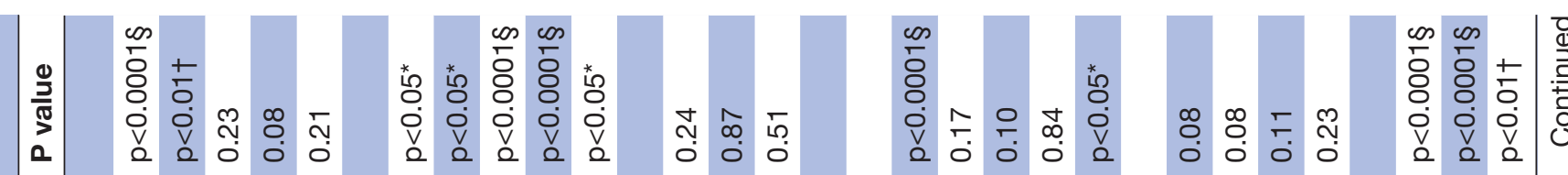

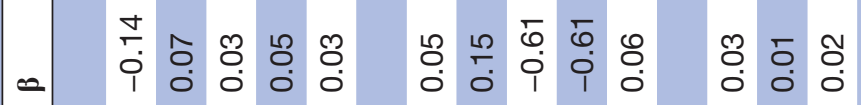

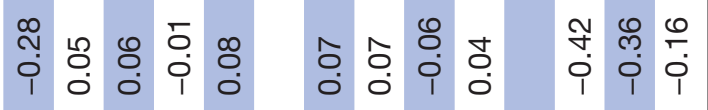

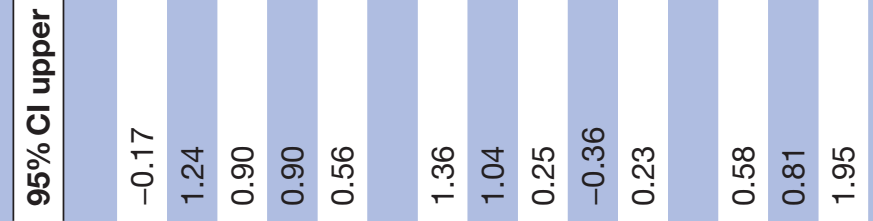

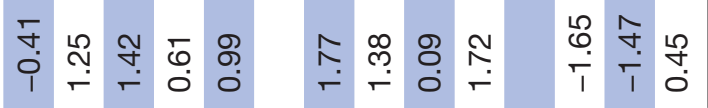

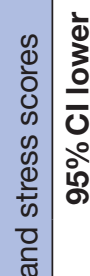

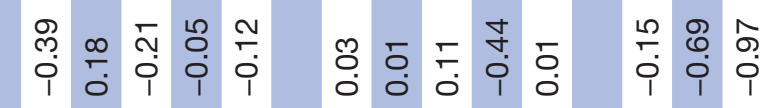

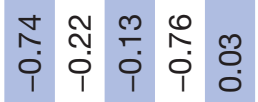

은ำ

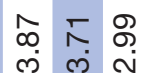

을

$\frac{\mathscr{0}}{\frac{0}{0}}$

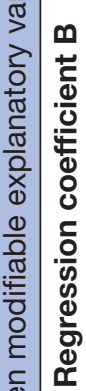

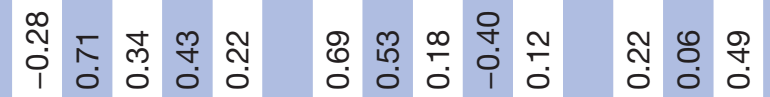

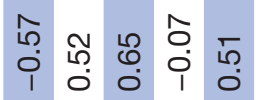

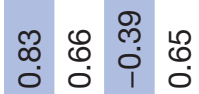

$\stackrel{1}{\sim}$

离

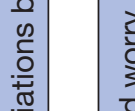

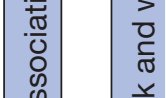

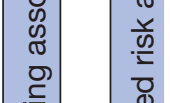

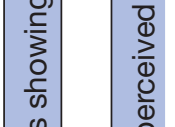

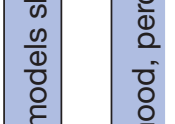

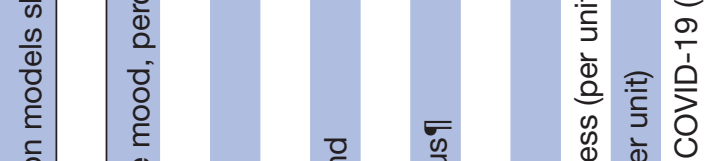

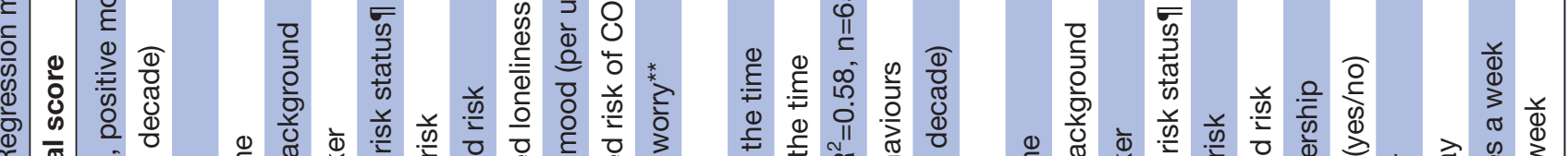

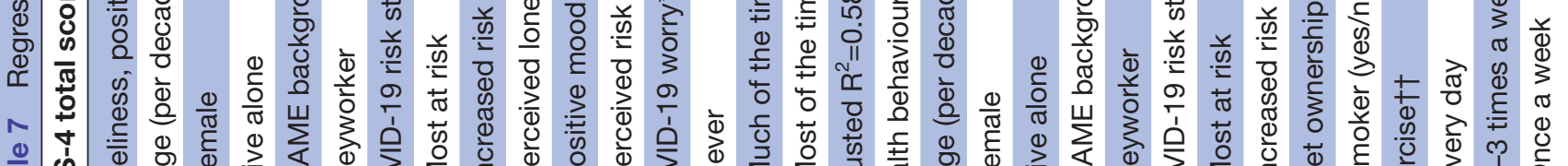

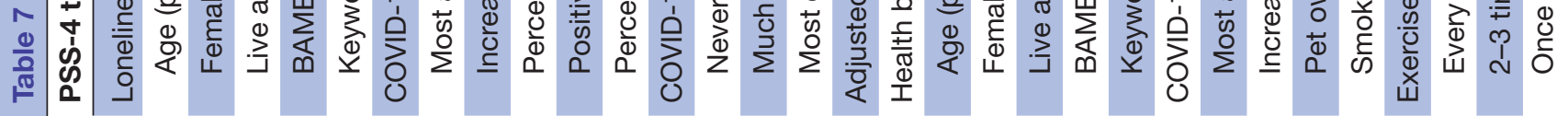




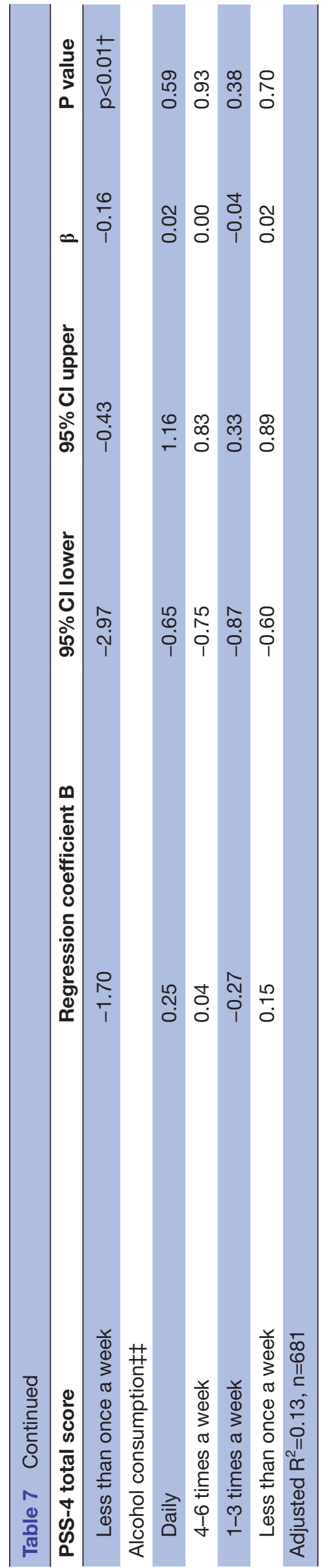

symptoms, ${ }^{42-44}$ but may worsen mental well-being in the long term. ${ }^{45}$

Healthy behaviours such as exercise and pet ownership were found to be protective factors for poorer mental health during the first 10 weeks of the pandemic. It was expected that individuals who own a pet $(\mathrm{eg}, \mathrm{dog})$ may be more likely to exercise, but no correlation was found between these variables. Participants may have owned animals that do not require exercising (eg, cats, rabbits or fish). The benefits of exercise, as well as animal companionship are well documented in the literature on mental health. Exercise is known to improve cerebral blood flow, sleep, mental alertness, self-esteem and energy, and prevent social withdrawal. ${ }^{4647}$ It may also provide a distraction to daily challenges. ${ }^{47}$ Studies on animal contact have also reinforced the positive impacts on mood and physiological responses such as reductions in cortisol, blood pressure and heart rate. ${ }^{48-50}$ Indeed, pets may have also provided a welcome distraction and companionship during the pandemic, even though loneliness was not lower in pet owners.

Population-based interventions during the remainder of the COVID-19 pandemic and future pandemics should promote exercise and positive mood and target loneliness, and excessive alcohol and tobacco consumption. While pet ownership was also a protective factor, it is impractical to promote purchasing pets. Upstream approaches should include targeting the consequences of social isolation, such as loneliness. ${ }^{40}$ Maguire and Looi ${ }^{51}$ support the need to target loneliness, stating that more targeted strategies to combat boredom and loneliness during the COVID-19 pandemic (especially when socially isolating) are required for people with mental health needs, such as schizophrenia. Accordingly, psychiatrists should be included in informing public health approaches, such as by leveraging social media to disseminate messages of support ${ }^{52}$ and to promote healthy behaviours. This may also help to mitigate the impacts of social isolation. Other interventions that may be effective in reducing anxiety and depression during the COVID-19 pandemic include cognitive behavioural therapy, which can be made available online or over smartphones. ${ }^{53}$

When adjusting for age and gender differences, anxiety and stress were significantly lower in the NZ sample than the UK sample. Worry about COVID-19 and levels of perceived risk of COVID-19 were also lower in the NZ sample. Possible explanations may be due to significantly more cases of COVID-19 and related mortalities reported in the UK than NZ. ${ }^{4}$ The difference in numbers of cases may have resulted in the UK sample feeling more at risk and anxious of being infected. Likewise, different restrictions in social distancing and containment efforts across both countries may have made the UK sample feel less protected and more exposed to the virus. However, overall mean scores for depression were not significantly different in the NZ sample compared with the UK sample. ${ }^{20}$

Due to the cross-sectional nature of the study, caution must be exercised when firmly concluding that the 
COVID-19 pandemic caused the mental health status reflected in the data. The nature of the study also means we cannot comment on causal associations or be certain of the direction of the relationships (eg, lower positive mood may lead to greater depression and vice versa). More longitudinal research is required to fully explore the ongoing impacts of COVID-19. The sample consisted of a relatively small proportion of the total NZ population, and therefore may not be representative. The sample was predominantly female $(89 \%)$, and only $2.1 \%$ identified as Māori, compared with $16.5 \%$ of the total NZ population. ${ }^{54}$ The online delivery of the survey may have introduced selection bias. The survey also featured selfreported (although validated) questionnaires to measure psychiatric symptoms and did not make clinical diagnoses. The gold standard for establishing psychiatric diagnoses involves structured clinical interview and functional neuroimaging. ${ }^{55-57}$ Response bias may have also been evident, whereby individuals who were more anxious, stressed and perceived to be impacted by the pandemic may have been more likely to participate. This could result in worse mental well-being reflected in the data. These factors may limit the generalisability of the results. Research that includes stress hormones (ie, cortisol) is also required to measure biological correlates of stress.

The cross-sectional method allowed for multiple modifiable and non-modifiable variables to be explored, as well as their associations with validated measures for depression, anxiety, stress and positive mood. A significant strength of the study included using a similar design and survey to the study by Jia $e t a t^{20}$ conducted on a UK cohort during the COVID-19 pandemic. This allowed for accurate comparisons to be made.

\section{CONCLUSION}

This study explored the mental health status of a NZ population during the first 10 weeks of the COVID-19 pandemic. As the first study to explore mental well-being in this population during the pandemic, the findings add to a body of knowledge on how mental well-being has been impacted. It also contributes a number of novel insights on protective behaviours. Overall, the NZ population had greater levels of depression and anxiety during the first 10 weeks of the COVID-19 pandemic, compared with population norms. People who are younger and most at risk of COVID-19 experienced poorer mental health. The NZ population reported lower levels of anxiety and stress than a UK sample, when adjusting for differences in age and gender. The NZ sample also reported lower perceived risk of COVID-19 and less worry about COVID-19, than the UK sample. The findings revealed that smoking and alcohol were associated with poorer mental well-being, and that pet ownership and exercise were protective factors. Future population-based interventions could promote frequent exercise, positive mood and pet ownership, and target loneliness and unhealthy behaviours, especially among young adults.
Twitter Norina Gasteiger @NorinaGasteiger, Kavita Vedhara @kavitavedhara, Ru Jia @RJ_ruthj and Elizabeth Broadbent @LizBroadbent

Contributors All authors (NG, KV, AM, RJ, KY, TC, CC and EB) contributed to the study design, interpretations of the findings and consented to the final version of the manuscript before submission to the publisher. NG and EB also managed recruitment, collected and analysed the data, and prepared the first draft of the manuscript.

Funding The authors have not declared a specific grant for this research from any funding agency in the public, commercial or not-for-profit sectors.

Competing interests None declared.

Patient consent for publication Not required.

Ethics approval The Auckland Health Research Ethics Committee in NZ approved this cohort study on 5 May 2020 (Ref: AH1326).

Provenance and peer review Not commissioned; externally peer reviewed.

Data availability statement No data are available. Participants of this study did not agree for their data to be shared publicly, so supporting data are not available.

Supplemental material This content has been supplied by the author(s). It has not been vetted by BMJ Publishing Group Limited (BMJ) and may not have been peer-reviewed. Any opinions or recommendations discussed are solely those of the author(s) and are not endorsed by BMJ. BMJ disclaims all liability and responsibility arising from any reliance placed on the content. Where the content includes any translated material, BMJ does not warrant the accuracy and reliability of the translations (including but not limited to local regulations, clinical guidelines, terminology, drug names and drug dosages), and is not responsible for any error and/or omissions arising from translation and adaptation or otherwise.

Open access This is an open access article distributed in accordance with the Creative Commons Attribution Non Commercial (CC BY-NC 4.0) license, which permits others to distribute, remix, adapt, build upon this work non-commercially, and license their derivative works on different terms, provided the original work is properly cited, appropriate credit is given, any changes made indicated, and the use is non-commercial. See: http://creativecommons.org/licenses/by-nc/4.0/.

\section{ORCID iDs}

Norina Gasteiger http://orcid.org/0000-0001-7801-7417

Kavita Vedhara http://orcid.org/0000-0002-9940-7534

Elizabeth Broadbent http://orcid.org/0000-0003-3626-9100

\section{REFERENCES}

1 World Health Organization. COVID-19 as a public health emergency of international concern (PHEIC) under the IHR, 2020. Available: https://extranet.who.int/sph/covid-19-public-health-emergencyinternational-concern-pheic-under-ihr

2 Department of Health. First confirmed case of novel coronavirus in Australia, 2020. Available: https://www.health.gov.au/ministers/thehon-greg-hunt- $\mathrm{mp} /$ media/first-confirmed-case-of-novel-coronavirusin-australia

3 Ministry of Health. COVID-19 - current cases, 2020. Available: https://www.health.govt.nz/our-work/diseases-and-conditions/covid19-novel-coronavirus/covid-19-current-situation/covid-19-currentcases

4 John Hopkins University. COVID-19 Dashboard by the center for systems science and engineering (CSSE) at John Hopkins University, 2020. Available: https://coronavirus.jhu.edu/map.html

5 Sohrabi C, Alsafi Z, O'Neill N, O'Neill N, et al. World Health organization declares global emergency: a review of the 2019 novel coronavirus (COVID-19). Int J Surg 2020;76:71-6.

6 Department of Health and Social Care and Public Health England. Coronavirus cases in the UK: daily updated statistics, 2020. Available: https://www.gov.uk/guidance/coronavirus-covid-19information-for-the-public

7 Xiong J, Lipsitz O, Nasri F, et al. Impact of COVID-19 pandemic on mental health in the general population: a systematic review. J Affect Disord 2020;277:55-64.

8 Zhou F, Yu T, Du R, et al. Clinical course and risk factors for mortality of adult inpatients with COVID-19 in Wuhan, China: a retrospective cohort study. Lancet 2020;395:1054-62.

9 Khunti K, Singh AK, Pareek M, et al. Is ethnicity linked to incidence or outcomes of covid-19? BMJ 2020;369:m1548.

10 Liu S, Yang L, Zhang C. Online mental health services in China during the COVID19 outbreak. Lancet Psychiatry 2020;18:e17-18. 
11 Tian F, Li H, Tian S, et al. Psychological symptoms of ordinary Chinese citizens based on SCL-90 during the level I emergency response to COVID-19. Psychiatry Res 2020;288:112992.

12 Wang C, Chudzicka-Czupała A, Grabowski D, et al. The association between physical and mental health and face mask use during the COVID-19 pandemic: a comparison of two countries with different views and practices. Front Psychiatry 2020;11:569981.

13 Tran BX, Nguyen HT, Le HT, et al. Impact of COVID-19 on economic well-being and quality of life of the Vietnamese during the National social distancing. Front Psychol 2020;11:565153.

14 Bao Y, Sun Y, Meng S, et al. 2019-nCoV epidemic: address mental health care to empower Society. Lancet 2020;395:e37-8.

15 Holmes EA, O'Connor RC, Perry VH, et al. Multidisciplinary research priorities for the COVID-19 pandemic: a call for action for mental health science. Lancet Psychiatry 2020;7:547-60.

16 Wang C, Pan R, Wan X, et al. A longitudinal study on the mental health of general population during the COVID-19 epidemic in China. Brain Behav Immun 2020;87:40-8.

17 Hawryluck L, Gold WL, Robinson S, et al. Sars control and psychological effects of quarantine, Toronto, Canada. Emerg Infect Dis 2004;10:1206-12.

18 Jeong H, Yim HW, Song Y-J, et al. Mental health status of people isolated due to middle East respiratory syndrome. Epidemiol Health 2016;38:e2016048.

19 Rajkumar RP. COVID-19 and mental health: a review of the existing literature. Asian J Psychiatr 2020;52:102066.

20 Jia R, Ayling K, Chalder T, et al. Mental health in the UK during the COVID-19 pandemic: cross-sectional analyses from a community cohort study. BMJ Open 2020;10:e040620.

21 Spitzer RL, Kroenke K, Williams JBW, et al. A brief measure for assessing generalized anxiety disorder: the GAD-7. Arch Intern Med 2006;166:1092-7.

22 Kroenke K, Spitzer RL, Williams JBW, et al. The patient health questionnaire somatic, anxiety, and depressive symptom scales: a systematic review. Gen Hosp Psychiatry 2010;32:345-59.

23 Cohen S, Williamson G. Perceived stress in a probability sample of the United States. In: Spacapam S, Oskamp S, eds. The social psychology of health: claremont symposium on applied social psychology. Newbury Park: California, 1988: 31-67.

24 Diener E, Wirtz D, Tov W, et al. New well-being measures: short scales to assess Flourishing and positive and negative feelings. Soc Indic Res 2010:97:143-56.

25 Kocalevent R-D, Hinz A, Brähler E. Standardization of the depression screener patient health questionnaire (PHQ-9) in the general population. Gen Hosp Psychiatry 2013;35:551-5.

26 Löwe B, Decker O, Müller S, et al. Validation and standardization of the generalized anxiety disorder screener (GAD-7) in the general population. Med Care 2008;46:266-74.

27 Warttig SL, Forshaw MJ, South J, et al. New, normative, Englishsample data for the short form perceived stress scale (PSS-4). $J$ Health Psychol 2013;18:1617-28.

28 Tee ML, Tee CA, Anlacan JP, et al. Psychological impact of COVID-19 pandemic in the Philippines. J Affect Disord 2020;277:379-91.

29 Wang C, Pan R, Wan X, et al. Immediate psychological responses and associated factors during the initial stage of the 2019 coronavirus disease (COVID-19) epidemic among the general population in China. Int J Environ Res Public Health 2020;17:1729.

30 Cao W, Fang Z, Hou G, et al. The psychological impact of the COVID-19 epidemic on college students in China. Psychiatry Res 2020;287:112934.

31 Hatch SL, Dohrenwend BP. Distribution of traumatic and other stressful life events by race/ethnicity, gender, Ses and age: a review of the research. Am J Community Psychol 2007;40:313-32.

32 McManus S, Bebbington P, Jenkins R. Mental health and wellbeing in England: adult psychiatric morbidity survey 2014. NHS: Leeds, 2016.

33 Ministry of Health. 2018/19: new Zealand health survey, 2019. Available: https://minhealthnz.shinyapps.io/nz-health-survey-201819-annual-data-explorer/
34 Clark C, Pike C, McManus S, et al. The contribution of work and non-work stressors to common mental disorders in the 2007 adult psychiatric morbidity survey. Psychol Med 2012;42:829-42.

35 Mental Health Foundation. Stress: are we coping? London: Mental Health Foundation, 2018.

36 Diener E, Emmons RA. The independence of positive and negative affect. J Pers Soc Psychol 1984;47:1105-17.

37 Huppert FA, Whittington JE. Evidence for the independence of positive and negative well-being: implications for quality of life assessment. Br J Health Psychol 2003;8:107-22.

38 De Silva MJ, McKenzie K, Harpham T, et al. Social capital and mental illness: a systematic review. J Epidemiol Community Health 2005;59:619-27.

39 Wang $\mathrm{HH}$. A meta-analysis of the relationship between social support and well-being. Kaohsiung J Med Sci 1998;14:717-26.

40 Leigh-Hunt N, Bagguley D, Bash K, et al. An overview of systematic reviews on the public health consequences of social isolation and loneliness. Public Health 2017;152:157-71.

41 Lipari R, Van Horn S. The CBHSQ report: smoking and mental illness among adults in the United States. The CBHSQ report. Rockville: Substance Abuse and Mental Health Services Administration, 2017.

42 Boden JM, Fergusson DM, Horwood LJ. Cigarette smoking and depression: tests of causal linkages using a longitudinal birth cohort. Br J Psychiatry 2010;196:440-6.

43 Bolton JM, Robinson J, Sareen J. Self-Medication of mood disorders with alcohol and drugs in the National epidemiologic survey on alcohol and related conditions. J Affect Disord 2009;115:367-75.

44 Taylor G, McNeill A, Girling A, et al. Change in mental health after smoking cessation: systematic review and meta-analysis. BMJ 2014;348:g1151.

45 Munafò MR, Araya R. Cigarette smoking and depression: a question of causation. Br J Psychiatry 2010;196:425-6.

46 Callaghan P. Exercise: a neglected intervention in mental health care? J Psychiatr Ment Health Nurs 2004;11:476-83.

47 Peluso MAM, Guerra de Andrade LHS, Andrade L. Physical activity and mental health: the association between exercise and mood. Clinics 2005;60:61-70.

48 Allen K, Blascovich J, Mendes WB. Cardiovascular reactivity and the presence of pets, friends, and spouses: the truth about cats and dogs. Psychosom Med 2002;64:727-39.

49 Barker SB, Knisely JS, McCain NL, et al. Measuring stress and immune response in healthcare professionals following interaction with a therapy dog: a pilot study. Psychol Rep 2005;96:713-29.

50 Beetz A, Kotrschal K, Turner DC, Hediger K, et al. The effect of a real dog, toy dog and friendly person on Insecurely attached children during a stressful task: an exploratory study. Anthrozoos 2011;24:349-68.

51 Maguire PA, Looi JCL. Vulnerability of people with schizophrenia to COVID-19. Aust N Z J Psychiatry 2020;54:1044.

52 Singh AB. What's the psychiatrist's role in the COVID-19 outbreak? Aust N Z J Psychiatry 2020;54:759

53 Ho CS, Chee CY, Ho RC. Mental health strategies to combat the psychological impact of COVID-19 beyond paranoia and panic. Ann Acad Med Singap 2020;49:155-60.

54 Statistics New Zealand. 2018 census population and dwelling counts, 2019. Available: https://www.stats.govt.nz/informationreleases/2018-census-population-and-dwelling-counts

55 Husain SF, Yu R, Tang T-B, et al. Validating a functional near-infrared spectroscopy diagnostic paradigm for major depressive disorder. Sci Rep 2020;10:9740.

56 Husain SF, Ong SK, Cuizhen L, et al. Functional near-infrared spectroscopy during a decision-making task in patients with major depressive disorder. Aust N Z J Psychiatry 2020:000486742097685.

57 Ho CSH, Lim LJH, Lim AQ, et al. Diagnostic and predictive applications of functional near-infrared spectroscopy for major depressive disorder: a systematic review. Front Psychiatry 2020;11:378. 